\title{
Interférences
}

Ars scribendi

$8 \mid 2015$

L'exil au miroir de la Correspondance de Cicéron

\section{Délibération, conseil et prise de décision dans les lettres d'exil de Cicéron}

\section{Charles Guérin}

\section{(2) OpenEdition \\ 1 Journals}

Édition électronique

URL : http://journals.openedition.org/interferences/5509

DOI : 10.4000/interferences.5509

ISSN : 1777-5485

Éditeur

HiSoMA - Histoire et sources des Mondes antiques

Référence électronique

Charles Guérin, « Délibération, conseil et prise de décision dans les lettres d'exil de Cicéron »,

Interférences [En ligne], 8 | 2015, mis en ligne le 31 octobre 2014, consulté le 15 septembre 2020. URL : http://journals.openedition.org/interferences/5509; DOI : https://doi.org/10.4000/interferences.5509

Ce document a été généré automatiquement le 15 septembre 2020.

Tous droits réservés 


\title{
Délibération, conseil et prise de décision dans les lettres d'exil de Cicéron
}

\author{
Charles Guérin
}

1 Dans les réflexions que Cicéron consacre à la pratique épistolaire, et en particulier dans les typologies qu'il propose à plusieurs occasions ${ }^{1}$, l'idée que la lettre et l'échange avec un correspondant représentent un support et un vecteur de la décision n'est jamais explicitement formulée. Sans doute est-ce parce que les discussions consacrées aux affaires publiques ou privées, qui constituent d'après lui des genera epistolarum classiques, ne valent que si elles aboutissent à une action, un conseil ou au moins une délibération, au point que cette dimension n'a pas besoin d'être théorisée. La prise de décision, les conseils et les délibérations forment pourtant une partie essentielle de la correspondance cicéronienne, qui souvent en rend compte, les réclame ou en critique le résultat. C'est d'ailleurs pour obtenir d'Atticus qu'il le rejoigne et délibère avec lui sur la conduite à tenir que Cicéron lui adresse sa première lettre d'exil, très courte, de mars 58, alors qu'il vient tout juste de quitter Rome (Cic., Att. 3, 1) :

Cum antea maxime nostra interesse arbitrabar te esse nobiscum, tum uero, ut legi rogationem, intellexi ad iter id quod constitui nihil mihi optatius cadere posse quam ut tu me quam primum consequare, ut, cum ex Italia profecti essemus, siue per Epirum iter esset faciendum tuo tuorumque praesidio uteremur, siue aliud quid agendum esset, certum consilium de tua sententia capere possemus.

Avant d'avoir lu la proposition de loi, j'estimais déjà que j'avais tout intérêt à ce que tu m'accompagnes; maintenant que je l'ai lue, j'ai compris que tout ce que j'avais à souhaiter, pour ce voyage que j'ai décidé, c'était que tu me rejoignes aussi vite que possible : ainsi, une fois que j'aurai quitté l'Italie, je voyagerai sous ta protection et celle des tiens si je dois traverser l'Épire, et si je dois faire autrement, je pourrai m'appuyer sur ton avis pour prendre ma décision ${ }^{2}$.

La conduite à tenir (agere) sera adoptée à la suite d'une prise de décision réfléchie (consilium capere), elle-même éclairée par l'avis d'Atticus (tua sententia). Mais Atticus, on le sait, ne rejoindra jamais Cicéron ${ }^{3}$, qui, après quelques lettres ${ }^{4}$, finira par abandonner 
l'idée d'une délibération en face à face: la correspondance jouera alors son rôle traditionnel de sermo de substitution ${ }^{5}$.

3 La volonté de former un consilium aussi pertinent que possible sur la marche à suivre ne quittera pas Cicéron pour autant: toutes les lettres d'exil martèlent la nécessité d'évaluer la situation, de peser les choix possibles et, finalement, d'arriver à la bonne décision, pour lui comme pour ses soutiens, celle qui assurera la sécurité des siens et son retour à Rome. Pourtant, la manière dont ces lettres présentent les différents consilia de Cicéron et de son entourage est singulière dans l'ensemble de la correspondance. En premier lieu, la situation dans laquelle se trouve Cicéron en 58 et 57 av. J.-C. rend particulièrement délicat un processus de décision qui, en temps normal, est déjà difficile, comme il l'écrit à Lentulus lorsqu'il lui apporte ses conseils dans l'affaire d'Égypte : trancher entre deux lignes de conduite ou décider en faisant des conjectures sur l'évolution d'une situation n'est pas chose aisée ${ }^{6}$. Mais en exil, quels choix sont véritablement laissés à Cicéron? Et de quels moyens de délibération dispose-t-il réellement? Comme il le confesse à Terentia, dans ces circonstances défavorables, la réflexion pratique et les choix qu'elle suppose lui sont rendus plus difficiles encore qu'à l'habitude : Cicéron semble avoir perdu toute capacité de décision et le reconnaît lui-même ${ }^{7}$.

4 Cette difficulté et cette incapacité que Cicéron rappelle à plusieurs reprises ont nourri une tradition négative et anti-cicéronienne virulente. Elles s'expliquent pourtant assez bien, sans qu'il soit besoin de s'abandonner aux réflexions malveillantes et politiquement orientées ${ }^{8}$ de Jérôme Carcopino ${ }^{9}$ : à mesure que l'exil se prolonge, Cicéron prend conscience et reconnaît que sa situation tient, au premier chef, à une mauvaise décision. Son départ était une erreur, et c'est ce choix qui l'a précipité dans le malheur ${ }^{10}$. Toutes les décisions à prendre au cours de son exil sont comme alourdies par le souvenir de cette faute et, dans le corpus d'exil, sans doute par un effet de sélection ${ }^{11}$, les décisions prises par le passé tiennent une place aussi importante que les décisions qui restent à prendre: elles transforment les lettres en support de ressassement et de regret autant qu'en support de réflexion.

5 Le consilium et le risque qui l'accompagne apparaissent donc sous deux aspects dans les lettres d'exil : celui d'une délibération qu'il faut mener, mais qui échappe sans cesse, celui d'une erreur passée sur laquelle on médite. Dans ces conditions, on doit se demander à quoi servent véritablement les débats portant sur les décisions à prendre dans ces lettres, et je tenterai de montrer qu'ils visent moins à offrir un réel support de délibération qu'à construire l'image de l'épistolier en vue d'influencer le comportement de ses destinataires.

\section{Délibérer en exil : un processus évanescent}

6 Cicéron exerce son choix sur trois objets : les lieux de l'exil, les modalités du rappel et ses affaires familiales. Naturellement, son départ précipité met au premier plan la question la plus urgente, celle de la fuite et du repli dans une résidence sûre. Par conséquent, les premières délibérations du corpus sont géographiques. Il faut en effet faire des choix, celui d'un lieu et celui d'un parcours, et c'est pour prendre ces décisions que Cicéron attend le secours d'Atticus, qui doit le rejoindre pour l'aider dans cette démarche (Cic., Att. 3, 3) : 
Sed te oro ut ad me Vibonem statim uenias, quo ego multis de causis conuerti iter meum. Sed eo si ueneris, de toto itinere ac fuga mea consilium capere potero ${ }^{12}$.

Viens tout de suite me retrouver à Vibo, je t'en prie: j'ai changé ma route pour différentes raisons, et c'est là que je vais. Mais si tu te rends là-bas, c'est sur mon voyage et mon exil dans leur ensemble que je pourrai prendre une décision.

7 La manière dont Cicéron formule sa demande montre que cet objet de délibération apparemment simple ne lui laisse en définitive aucune latitude. Il décide bien peu et s'adapte aux circonstances. Ce sont elles qui lui ont imposé son itinéraire (multis de causis conuerti), comme il s'en explique dans la lettre suivante (Cic., Att. 3, 2) :

Itineris nostri causa fuit quod non habebam locum ubi pro meo iure diutius esse possem quam fundum Siccae, praesertim nondum rogatione correcta; et simul intellegebam ex eo loco, si te haberem, posse me Brundisium referre, sine te autem non esse nobis illas partes tenendas propter Autronium. Nunc, ut ad te antea scripsi, si ad nos ueneris, consilium totius rei capiemus.

Si j'ai pris cette route, c'est que la propriété de Sicca est le seul endroit où je sois libre de prolonger mon séjour, surtout quand la proposition de loi n'a pas encore été amendée. Et puis j'avais également en tête que, si je t'avais avec moi, je pourrais retourner à Brindes, alors que sans toi, il valait mieux ne pas aller par là - à cause d'Autronius. Bon, comme je te l'ai déjà écrit, si tu viens à ma rencontre, nous pourrons arrêter un plan complet.

8 La première raison de son installation chez Sicca était la quête de sécurité ${ }^{13}$. Mais le manque d'informations (nondum rogatione correcta) jouait aussi son rôle : comme il ne savait pas encore ce qui lui serait imposé, un séjour chez Sicca était, en définitive, le choix qui lui laissait ouvert le plus grand nombre de possibilités. Une part de liberté demeure donc, Cicéron annonçant qu'il tranchera plus tard sur sa destination finale (consilium totius rei capiemus).

9 La réalité de sa situation lui apparaît le 13 avril 58, lorsqu'il reçoit le contenu de la rogatio de Clodius et quitte précipitamment Sicca: cette rogatio lui fixe en effet une interdiction de 400 milles, mais la fait débuter immédiatement, ce qui impose à Cicéron de quitter les lieux ${ }^{14}$. Son départ, il y insiste, n'est pas dû à un changement d'avis qui découlerait de son irrésolution (inconstantia), mais dépend simplement des circonstances et des malheurs qui l'accablent (miseriae) (Cic., Att. 3, 4) :

Miseriae nostrae potius uelim quam inconstantiae tribuas quod a Vibone quo te arcessebamus subito discessimus. Adlata est enim nobis rogatio de pernicie mea, in qua quod correctum esse audieramus erat eius modi ut mihi ultra quadringenta milia liceret esse, illuc peruenire non liceret. Statim iter Brundisium uersus contuli ante diem rogationis, ne et Sicca, apud quem eram, periret et quod Melitae esse non licebat.

Je t'en prie, accuse mon malheur, et non ma légèreté, si j'ai quitté précipitamment Vibo, où je t'avais donné rendez-vous. C'est qu'on m'a apporté le texte de la proposition de loi qui cause ma ruine, et l'amendement dont j'avais entendu parler est rédigé de telle sorte que j'ai le droit de m'installer à une distance de quatre cents milles, mais qu'on ne me laisse pas les moyens d'aller jusque là. Je me suis aussitôt empressé de faire route vers Brindes avant le vote de la loi, parce que je ne voulais pas causer la perte de Sicca, chez qui j'étais, et parce que le séjour de Malte m'était refusé ${ }^{15}$.

$\mathrm{Nul}$ choix ici, mais une simple réponse à la pression des événements : Cicéron se rend à Brindes pour éviter que Sicca ne tombe lui-même sous le coup de la loi ${ }^{16}$, mais aussi parce que $C$. Vergilius, le gouverneur de Sicile, lui a refusé l'asile ${ }^{17}$. En d'autres termes, il ne décide pas de se rendre à Brindes, mais s'y résout. À l'inverse, à son retour d'exil, la correspondance qu'il entretient avec son frère donne l'exemple d'une véritable prise de décision sur des sujets semblables (Cic., Q. fr. 2, 5, 4) : 
[...] postridie autem in Laterio cogitabam, inde, cum in Arpinati quinque dies fuissem, ire in Pompeianum, rediens aspicere Cumanum [...].

[...] le lendemain, je me propose d'être à ton Latérium et de là, après avoir séjourné cinq jours dans ma villa d'Arpinum, d'aller dans ma propriété de Pompéi ; au retour, de jeter un coup d'œil sur ma villa de Cumes [...] ${ }^{18}$.

11 Une fois retrouvée sa liberté de mouvement, Cicéron peut à nouveau délibérer sur sa villégiature et son parcours. L'urgence qui marque ses réactions d'avril 58 n'en apparaît que plus vivement.

Néanmoins, une fois respectée la distance légale, l'exilé a toute latitude pour s'installer où il le souhaite ${ }^{19}$ : il délibère à nouveau sur ces sujets et pèse les différentes possibilités qui s'offrent à lui. Il peut alors annoncer à son correspondant quelle voie il a préféré emprunter (Att. 3, 6: nobis iter est in Asiam, maxime Cyzicum ; Fam. 14, 4, 3 : per Macedoniam Cyzicum petebamus), ou expliquer ses choix d'installation. Si la contrainte existe toujours, la réflexion de Cicéron peut désormais intégrer d'autres paramètres que le seul danger physique : la distance, la facilité des communications, les rencontres possibles. Il s'agit donc d'un domaine où Cicéron exerce une véritable capacité de choix : il ne demande pas l'avis de ses correspondants, mais expose sa décision et la justifie en fournissant les raisons de son installation dans chaque lieu. En Att. 3, 8, 1, il explique sa décision de se rendre à Thessalonique sans passer par l'Épire par sa volonté de rester à bonne distance des partisans de Catilina exilés, de prendre des routes plus praticables et, enfin, de faciliter sa rencontre avec son frère. En Fam. 14, 1, 7, il explique à Terentia son installation à Dyrrachium en ces termes :

Dyrrachium ueni, quod et libera ciuitas est et in me officiosa et proxima Italiae [...].

Je suis venu à Dyrrachium parce que c'est une ville libre, parce qu'elle m'est dévouée, parce qu'elle est près de l'Italie [...] ${ }^{20}$.

13 À la sécurité s'ajoutent les avantages de la proximité. Il ne s'agit certes pas d'un choix original, puisque Dyrrachium est le lieu où s'installe la majorité des exilés dont nous avons gardé la trace - du moins, parmi eux, ceux qui conservent l'espoir du retour ${ }^{21}$. Pour autant, Cicéron n'est plus ballotté par les événements comme en Italie : il décide et dispose d'un certain espace de liberté. Peut-être est-ce d'ailleurs le seul.

En effet, les autres domaines où des décisions doivent être prises font apparaître chez Cicéron une impuissance et une incapacité qu'il déplore lui-même. Certes, il parvient à délibérer sur les affaires qu'il considère comme de peu d'importance, comme dans l'échange du 29 avril 58 avec Terentia, où il est question de l'affranchissement des esclaves de leur familia. Dans cette lettre, il présente clairement ses arguments et tranche, selon une méthode sur laquelle je reviendrai, en exposant les différentes possibilités sous forme de disputatio et de disjonctions (Cic., Fam. 14, 4, 4) :

Primum tuis ita promissum est, te facturam esse ut quisque esset meritus [...]. Ceterorum seruorum ea causa est ut, si res a nobis abisset, liberti nostri essent, si obtinere potuissent ; sin ad nos pertinerent, seruirent, praeterquam oppido pauci.

D'abord les tiens n'ont reçu d'autre promesse que celle d'être traités par toi selon les mérites de chacun [...]. Quant aux autres esclaves, leur cas est le suivant : si mes biens ne m'appartenaient plus, ils seraient mes affranchis, à condition qu'ils réussissent à faire valoir leurs droits; s'ils continuaient à m'appartenir, ils demeureraient esclaves, excepté un tout petit nombre ${ }^{22}$.

Pour autant, et comme il y insiste lui-même, il s'agit là d'une affaire qui n'a pas grande importance (Sed haec minora sunt). À l'inverse, pour les enjeux vraiment lourds de conséquences, la décision est plus difficile, voire impossible. Que faire pour préserver Tullia et son mariage ? Cicéron abandonne la décision, car il est incapable de trancher. 
Il fournit donc à Terentia le but à atteindre sans lui indiquer les moyens d'y parvenir, et la laisse agir (Cic., Fam. 14, 4, 3) ${ }^{23}$ :

Sed quid Tulliola mea fiet ? iam id uos uidete; mihi deest consilium. Sed certe, quoquo modo se res habebit, illius misellae et matrimonio et famae seruiendum est.

Mais que deviendra ma chère petite Tullia? C'est à vous de vous en occuper, moi, je suis incapable de prendre une décision. Mais, quelle que soit la façon dont tournent les choses, il est certain qu'il faut tout faire pour préserver le mariage et la réputation de cette pauvre petite.

Cicéron ne dissimule donc pas que son consilium est en grande partie paralysé dès que l'on sort du domaine des minora.

De la même manière, les décisions concernant son rappel lui échappent par nature. La longue lettre du 29 novembre 58 (Att. 3, 23), où Cicéron critique la rogatio du 29 octobre 58 faite par les anciens tribuns ${ }^{24}$, illustre bien la situation : Cicéron en désapprouve le contenu, et en est réduit à réagir a posteriori précisément parce qu'il n'est pas intervenu dans le processus de décision. La lettre manie les hypothèses, formule des regrets, raille et, surtout, évoque la possibilité que la rogatio ait été faite dans de mauvaises intentions (suspicio malitiae alicuius, § 4) : on ne saurait mieux dire que Cicéron n'a pris aucune part à la délibération. La situation se répète tout au long de l'exil, et elle permet de voir combien Cicéron est privé de sa capacité d'agir sur les événements et de décider quoi que ce soit. Ainsi, lorsqu'il apprend que ses soutiens ont voté à l'avance l'ornatio des provinces, Cicéron espère qu'il y avait là un projet cohérent (sperabam uos aliquid aliquando uidisse prudentius, $\S 1$ ), puis constate qu'il n'en est rien : le 10 décembre (Att. 3, 24), il avoue son trouble (commotus), car cette mauvaise décision leur a aliéné les tribuns et a fragilisé sa propre position. Il commente, réagit, mais ne décide évidemment rien. Il ne peut qu'attendre les nouvelles qui lui apprendront l'issue de la manœuvre (Cic., Att. 3, 24, 2) :

Haec res quem ad modum ceciderit et tota res quo loco sit uelim ad me scribas.

Je t'en prie, dis moi comment les choses ont tourné, et où en est toute l'affaire.

Une seule fois, une décision est mentionnée sur ces questions, à propos du sénatusconsulte du $1^{\mathrm{er}}$ janvier 57 portant sur son rappel. Cette décision consiste à attendre que la demande de rappel passe par le peuple (Cic., Att. 3, 26) :

Litterae mihi a Quinto fratre cum senatus consulto quod de me est factum adlatae sunt. Mihi in animo est legum lationem exspectare.

J'ai reçu une lettre de mon frère Quintus avec le sénatus-consulte qui a été fait à mon sujet. J'ai l'intention d'attendre que la loi soit proposée au vote ${ }^{25}$.

18 On sait ce que donnera la tentative du 23 janvier 57 devant les comices, et le désespoir que suscitera l'échec de la manœuvre chez Cicéron ${ }^{26}$. Mais la sélection opérée dans la correspondance - peut-être pour créer un effet dramatique au sein des lettres à Atticus 27 - nous prive de tout échange entre février et septembre 57, et nous empêche de voir quel rôle Cicéron avait réellement joué dans le choix final de présenter une rogatio de rappel devant les comices centuriates ${ }^{28}$. Par conséquent, l'image qui nous est donnée par le corpus est celle d'un exilé qui ne peut exercer son consilium que sur des objets infimes, qui décide de ce qui le concerne hors de Rome mais certes pas dans la Cité.

Cet affaiblissement du consilium s'explique pour des raisons que Cicéron perçoit fort bien. Dans une lettre qu'il adresse à Atticus le 29 avril 58, il oppose deux raisons possibles à son hésitation à propos de l'Épire, l'inconstantia et l'incertitude (Cic., Att. 3, 7, 3) : 
Dubitationem autem de Epiro non inconstantia nostra adferebat sed quod de fratre, ubi eum uisuri essemus, nesciebamus [...].

Mes hésitations à propos de l'Épire, ce n'est pas mon irrésolution qui les a causées : c'est que je n'avais pas d'informations sur mon frère, et j'ignorais où nous pourrions nous rencontrer [...]. information : la dubitatio, qui est normalement la première phase de la décision, ne peut être dépassée ${ }^{29}$. Pour peser les possibilités qui s'offrent à lui, aussi réduites qu'elles soient, Cicéron doit disposer de l'information la plus pertinente possible : «si je savais ce qu'il en était, je saurais quoi faire» (si sciam cuius modi sit, sciam quid agendum mihi sit), affirme-t-il le 13 juin ${ }^{30}$.

21 C'est donc en s'appuyant sur les lettres de ses correspondants, dans leur rôle traditionnel et théorisé par ailleurs ${ }^{31}$ de vecteur d'information, que Cicéron pourra prendre ses décisions. Il le dit à Terentia quand elle lui propose une fois de plus de le rejoindre (Cic., Fam. 14, 3, 5) :

Ex primis aut summum secundis litteris tuis constituere poterimus quid nobis faciendum sit. Tu modo ad me uelim omnia diligentissime perscribas [...].

Je déciderai de la conduite à tenir d'après ta première lettre, ou d'après la seconde, mais il ne m'en faudra pas plus. Tout ce que je te demande, c'est de me faire un compte rendu extrêmement détaillé de tout cela [...].

L'incapacité à décider est donc à la mesure du caractère parcellaire des informations que reçoit l'exilé et de la difficulté des échanges entre Rome et la Macédoine ${ }^{32}$. Ainsi s'explique que Cicéron, tout au long de son exil, réclame non seulement des lettres ${ }^{33}$, mais surtout des lettres exhaustives ${ }^{34}$ et organisées de façon claire et précise ${ }^{35}$. L'enjeu, pour lui, est d'avoir une vision aussi complète que possible de la situation : $T u[. .$.$] quam$ plurimis de rebus ad me uelim scribas, ut prorsus ne quid ignorem, écrit-il à Atticus le 17 juin ${ }^{36}$.

Mais il est des circonstances où la faiblesse du consilium tient à l'état d'esprit de Cicéron. Dans ce cas, ce sont ses émotions qui lui interdisent toute délibération tant soit peu construite. Ainsi, après avoir expliqué que son départ subit de Vibo n'était pas dû à son irrésolution, mais aux événements ${ }^{37}$, Cicéron finit par reconnaitre son inconstantia. Celle-ci, comme il l'explique à Atticus le 29 mai 58, est traduite par ses lettres et résulte de l'émotion qui le tient (Cic., Att. 3, 8, 4):

Ex epistularum mearum inconstantia puto te mentis meae motum uidere, qui, etsi incredibili et singulari calamitate adflictus sum, tamen non tam est ex miseria quam ex culpae nostrae recordatione commotus.

$\mathrm{Tu}$ comprends, je pense, dans quel trouble je suis en constatant l'incohérence de mes lettres. Mais bien que j'aie été victime d'un désastre incroyable, unique, c'est moins la situation lamentable où je me trouve qui m'émeut que le souvenir de mon erreur ${ }^{38}$.

L'émotion, comme l'a montré Alessandro Garcea, paralyse la réflexion et se mue en uitium dans la mesure où elle interdit la cohérence et le maintien des choix ${ }^{39}$. Dans cet état d'agitation et d'abattement, Cicéron perd sa faculté de jugement : il s'en excusait déjà le 29 avril auprès de Terentia $(F a m .14,4)$, on l'a vu, mais il évoquera à nouveau cette difficulté auprès de son frère au mois d'août suivant, en lui demandant de tenir compte de son état quand il lui écrit. Puisque le courage et la faculté de prendre des décisions lui manquent, son correspondant doit s'adapter à son consilium affaibli (Cic., Q. fr. 1, 4, 5): 
Te oro ut ad me de omnibus rebus rescribas et in me animi aut potius consili minus putes esse quam antea [...].

Fais-moi un compte rendu de tout ce qui se passe, je t'en prie, et garde à l'esprit que mon courage, ou plutôt ma clairvoyance n'est plus ce qu'elle était [...]. une double fonction rationnelle: elles lui apportent les éléments permettant de décider, mais peuvent - ou non - le placer dans l'état psychique autorisant un raisonnement juste ${ }^{44}$. Cicéron évalue et discute la légitimité de l'espoir qu'il conçoit à partir des nouvelles qu'on lui donne ${ }^{45}$, et Atticus lui-même peut exposer en détail son point de vue sur la situation pour nourrir la spes de son correspondant ${ }^{46}$. Dès lors, il n'est pas étonnant que les décisions vacillent quand l'espoir disparaît. Quand les hésitations géographiques de Cicéron surgissent, c'est d'abord parce que l'espoir l'a abandonné. S'il renonce à se rendre en Épire contrairement à son projet, c'est faute d'un espoir suffisant (Cic., Att. 3, 13, 1) :

Quod ad te scripseram me in Epiro futurum, postea quam extenuari spem nostram et euanescere uidi, mutaui consilium nec me Thessalonica commoui, ubi esse statueram quoad aliquid ad me de eo scriberes quod proximis litteris scripseras [...].

Je t'avais écrit que j'irais en Épire, mais quand j'ai vu que notre espoir s'affaiblissait et s'évanouissait, j'ai changé d'avis et je n'ai pas bougé de Thessalonique: j'avais décidé de rester là jusqu'à ce que tu m'apprennes quelque chose au sujet de ce que tu m'avais écrit dans ta lettre précédente [... ${ }^{47}$.

Une fois encore, Cicéron justifie doublement sa mutatio consilii et illustre combien émotion et information sont inséparables dans la prise de décision. Mais dans ces conditions, l'on voit comment la volonté de l'exilé, quand elle n'est pas soutenue par l' expectatio boni ${ }^{48}$, peut s'effondrer. La suite de cet effondrement n'est pas un simple changement de consilium, mais l'incapacité à prendre une décision, quelle qu'elle soit. Ainsi, le 29 mai 58, Cicéron se torture au sujet de son frère sans aboutir à rien (Cic., Att. 3, 8, 3) :

Atque ita perturbato sum animo de Quinto ut nihil queam statuere [...].

Et je m'inquiète tant pour Quintus que je suis incapable de décider quoi que ce soit [...].

Cette paralysie de l'intellect peut atteindre un stade plus profond, au point de plonger Cicéron dans une hébétude et un mutisme inquiétants (Cic., Att. 3, 12, 3) :

Ego etiam nunc eodem in loco iaceo sine sermone ullo, sine cogitatione ulla.

Quant à moi, j'attends toujours au même endroit; je ne parle à personne, je ne pense à rien.

Cette opposition entre émotion et raison se fait plus nette encore quand Cicéron en explique la source véritable: non pas sa situation actuelle, mais sa cause, soit les trahisons dont il a été victime, les mauvais conseils qu'il a reçus, et, pour finir, 
l'exécrable décision qu'il a prise en quittant Rome ${ }^{49}$. Après avoir affirmé à Terentia que son exil était le résultat de sa vertu (dans un développement qui se voulait une sorte de consolatio, en Fam.14, 4, 5), Cicéron finit par assumer l'entière responsabilité de la catastrophe (omnia sunt mea culpa commissa, en Fam.14, 1, 1). Sa décision, par conséquent, est présentée comme un peccatum ${ }^{50}$, qu'il regrette dès les premières lettres à Atticus ${ }^{51}$.

Ce regret et sa mise en scène appuyée vont donner à Cicéron l'occasion d'explorer les conditions d'une prise de décision correcte. Car au-delà des tentatives de délibération au présent pendant l'exil, Cicéron se livre à une méditation sur la nature du bon consilium à partir du passé : c'est cette réflexion qui lui fournira le moyen de construire ses propres délibérations tout en lui permettant de poursuivre des fins stratégiques distinctes du processus de décision lui-même.

\section{Une réflexion sur les décisions passées}

31 La présentation chronologique de la correspondance rend très sensible la manière dont évolue la réflexion de Cicéron sur sa décision de quitter Rome. Commençant par se repentir, comme on l'a vu, il en vient à formuler explicitement des griefs : s'il a pris la mauvaise décision, c'est avant tout parce qu'il a reçu de mauvais conseils. Le reproche apparaît pour la première fois de manière floue en mai 58, dans la lettre 3,8 à Atticus ${ }^{52}$, puis le 13 juin, dans la lettre 1,3 à Quintus, où Cicéron explique que Hortensius et Arrius ont précipité sa ruine (Cic., Q. fr. 1, 3, 8) :

[...] quorum ego consiliis, promissis, praeceptis destitutus in hanc calamitatem incidi.

[...] c'est à cause de leurs décisions, de leurs promesses, de leurs conseils que j'ai été abandonné et que je suis tombé dans l'abîme où je me trouve ${ }^{53}$.

Deux mois plus tard, il affirmera à son frère qu'il a manqué de méfiance en prenant sa décision (cautum consilium, Q. fr. 1, 4, 1) et, en octobre 58, dans une lettre à Terentia, il regrettera de ne pas s'en être remis à son seul jugement (Cic., Fam. 14, 1, 2) :

Quod si nostris consiliis usi essemus neque apud nos tantum ualuisset sermo aut stultorum amicorum aut improborum, beatissimi uiueremus.

Ah! si je n'avais écouté que moi, si je m'étais moins fié à ce que me disaient mes amis - stupides ou perfides - quel bonheur j'aurais connu ${ }^{54}$ !

Comment comprendre cette erreur et, surtout, l'insistance avec laquelle elle est rappelée ? On pourrait répondre que Cicéron cherche uniquement là un moyen de faire retomber la faute sur autrui et d'alléger le poids de ses remords, mais ce serait méconnaître totalement le contexte épistolaire lui-même : les lettres de Cicéron ne sont pas un journal intime où il se livrerait, mais un outil de communication qui cherche à produire un effet sur le destinataire. Derrière ces déplorations et ces reproches, c'est donc bien un usage stratégique de cette thématique de l'erreur passée qu'il faut percevoir.

Tout au long des intrigues qui entourent le roi Ptolémée Aulète, Cicéron prodigue ses conseils à Lentulus ${ }^{55}$ : il lui fournit des informations, échange avec lui, le processus prend du temps et se fait dans des conditions où la réflexion est relativement libre, du moins pour Cicéron. C'est ce temps et cette liberté qui lui ont manqué dans les semaines qui ont précédé son départ, pris qu'il était par une peur irraisonnée (falsus timor), qui a obscurci son esprit jusqu'au furor ${ }^{56}$. Mais plus encore, s'il s'est fié à de mauvais conseillers, c'est que les bons lui ont fait défaut, comme il l'explique à Quintus. 
Ainsi qu'on l'a vu à propos du choix du trajet, la bonne décision ne peut en aucun cas se prendre seul : elle suppose des échanges, des discussions et une prise de conseil. Or, ceux qui auraient dû le conseiller correctement ne l'ont pas fait, Hortensius et les optimates lui ayant délibérément indiqué la mauvaise voie par perfidia ${ }^{57}$ et par inuidia ${ }^{58}$. Mais - et la chose est plus grave encore - Atticus lui-même ne lui a fourni aucun conseil, et c'est sur cet aspect de la thématique qu'il convient d'insister, car c'est lui qui révèle le mieux sa fonction stratégique.

Le reproche est suggéré une première fois à Atticus le 29 mai $\left(A t t .3,8,4{ }^{59}\right)$ et il est développé le 17 août $58($ Att. 3,15$)$ dans des termes très directs, qui deviendront plus aigres encore au retour d'exil, en septembre 57 (Att. 4, 1). L'analyse partira de la lettre du 17 août (Cic., Att. 3, 15, 4 et 7) :

Sed profecto si quantum me amas et amasti tantum amare deberes ac debuisses, numquam esses passus me, quo tu abundabas, egere consilio, nec esses passus mihi persuaderi utile nobis esse legem de collegiis perferri. Sed tu tantum lacrimas praebuisti dolori meo, quod erat amoris, tamquam ipse ego ; quod meritis meis perfectum potuit, ut dies ac noctes quid mihi faciendum esset cogitares, id abs te meo, non tuo scelere praetermissum est. [...] Nunc, Pomponi, quoniam nihil impertisti tuae prudentiae ad salutem meam, quod aut in me ipso satis esse consili decreras aut te nihil plus mihi debere quam ut praesto esses, quoniamque ego [...] me, meos tradidi inimicis inspectante et tacente te, qui, si non plus ingenio ualebas quam ego, certe timebas minus : si potes, erige adflictos et in eo nos iuua [...].

Mais vraiment, si tu me portes et m'as porté autant d'affection que tu devrais, que tu aurais dû le faire, jamais tu ne m'aurais laissé manquer de clairvoyance alors que tu en avais tant en réserve, et tu ne m'aurais pas laissé me convaincre que le vote de la loi sur les collèges servait mes intérêts. Mais toi, tu n'as eu, comme moi, que des larmes à opposer à ma souffrance - c'était ce que devait l'affection. Mais j'aurais pu mériter que tu consacres tes jours et tes nuits à peser ce qu'il me fallait faire : tu ne l'as pas fait, et c'est ma faute, pas la tienne. [...] Et maintenant, Pomponius, puisque tu n'as rien partagé avec moi de ton sens politique pour assurer mon salut, dans l'idée que j'avais assez de jugement par moi-même ou que tu ne me devais rien de plus que ta présence, et puisque [...] je me suis livré, moi et ma famille, à mes ennemis alors que toi, si tu n'avais pas plus d'esprit que moi, tu étais pourtant moins pris par la peur, eh bien si tu en as les moyens, relève-moi de terre et portemoi secours dans cette situation [...].

L'argument que Cicéron développe ici consiste à affirmer qu'Atticus a partagé sa douleur quand il aurait dû consacrer toute sa raison et sa réflexion à trouver la bonne solution (sed tu tantum lacrymas praebuisti dolori meo, §4). Si elle remplissait effectivement un officium ${ }^{60}$, cette émotion partagée en empêchait un autre, celui du conseil. Dans le De officiis, Cicéron fait du consilium une composante essentielle de l' amicitia, au même titre que le uictus communis ou que d'autres types d'interaction langagière (sermo, cohortatio, consolatio, obiurgatio) ${ }^{61}$. Dans la même manière, le Laelius insiste sur la nécessité de donner à ses amis des conseils de façon franche ${ }^{62}$, jusqu'à l' offensio ${ }^{63}$. C'est l'utilitas et la fides qui imposent cette franchise, et l'on comprend que le conseil n'est pas simplement rendu possible par l'amitié. Tout au contraire, c'est cette amitié qui transforme le conseil en devoir. Ainsi, en ne donnant aucun conseil à Cicéron, Atticus a commis une trahison ; l'amicus doit toujours apporter son conseil et y employer toute son énergie.

Cicéron, lorsqu'il appuie Lentulus dans ses intrigues égyptiennes, ne cesse de l'assurer qu'il consacre à l'affaire toute sa cura, toute sa diligentia et toutes ses cogitationes ${ }^{64}$ : Cicéron agit (agere) et réfléchit (cogitare) sans cesse ${ }^{65}$ pour servir les intérêts du proconsul, et ce sont précisément cette cogitatio et cette mise au service d'autrui de sa 
propre prudentia qui ont fait défaut chez Atticus - lui n'a pas consacré ses jours et ses nuits à trouver la meilleure solution comme il l'aurait dû. L'amicus a donc le devoir de conseiller, mais plus encore d'utiliser son intelligence pour apporter son aide: il ne s'agit pas de donner un avis à la légère, mais de produire une réflexion construite et informée pour éclairer celui qui, à l'image de Cicéron, n'est pas dans des conditions propices à la prise de décision. Puisque Cicéron était abattu, c'est Atticus qui est tenu pour responsable de ne pas l'avoir empêché de prendre la pire des décisions ( $a$ turpissimo consilio reuocaret, $\S 4$ ). On ne doit pas voir là un reproche excessif, comme le remarque Peter White ${ }^{66}$. Caelius, après s'être rendu dans le camp de César, reprochera à Cicéron de ne pas l'avoir empêché d'agir ainsi (Cic., Fam. 8, 17,1):

Nam mihi sentio bonam mentem iracundia et amore ablatam. Tu porro, cum ad te proficiscens Ariminum noctu uenissem, dum mihi pacis mandata das ad Caesarem et mirificum ciuem agis, amici officium neglexisti neque mi consuluisti. Neque haec dico quod diffidam huic causae, sed, crede mihi, perire satius est quam hos uidere.

Car je me rends compte que la colère et l'affection m'ont fait perdre la raison. Et toi, quand je t'ai fait une visite nocturne, à mon départ pour Ariminum, tu t'es conduit comme un merveilleux citoyen, en me confiant un message de paix pour César, mais tu as négligé les devoirs de l'amitié en ne t'intéressant pas à moi. Et je ne dis pas cela par manque de confiance dans le parti où je me trouve, mais crois-moi, mieux vaut la mort que de voir ces gens de près ${ }^{67}$.

La démarche est semblable à celle de Cicéron lorsqu'il adresse ses reproches à Atticus : Caelius, tout comme Cicéron, n'avait pas son bon sens, et son ami a négligé ses devoirs en ne lui accordant aucune attention véritable - et donc en ne faisant rien pour le retenir. C'est là une violation grave de l'officium, mais pourquoi insister sur cette difficulté?

La lettre ne représente assurément pas une déploration ou une simple plainte. Le propos est stratégique: l'insistance offre en réalité le moyen d'obtenir qu'Atticus participe désormais de la façon la plus active à la prise de décision. La lettre Att. 3, 15 répond à trois lettres d'Atticus, dont la première était toute de reproches et d'exhortations (una qua me obiurgas et rogas ut sim firmior, §1) et a visiblement mis Cicéron en fureur. Il y répond dès le $\$ 2$ par un développement aussi long que violent, où il établit le caractère exceptionnel de sa souffrance et interdit à Atticus d'utiliser à l'avenir le ton qu'il a employé dans sa dernière lettre ${ }^{68}$.

Le passage constitue un retournement complet des topiques usuelles de consolation ${ }^{69}$, mais il n'est pas pour autant un débordement de pathos, ni un apitoiement sur soi : il pose les fondements de la critique qui suit. Cicéron reproche à Atticus de se cantonner au rôle de consolateur dont il n'a nul besoin, puisqu'il n'est pas consolable. C'est d'ailleurs ce rôle de consolateur qui a ruiné Cicéron, puisqu'Atticus, en se contentant de pleurer avec lui, a oublié un devoir beaucoup plus essentiel et ne s'est pas engagé dans la décision à prendre. Le reproche quant à l'attitude passée se répercute donc sur le présent : Atticus doit maintenant mobiliser sa prudentia et fournir à Cicéron ce dont il a besoin pour prendre à l'avenir les meilleures décisions possible. De façon significative et rare dans la correspondance d'exil-, Cicéron passe à l'impératif et adopte un ton brutal (Cic., Att. 3, 15, 7) :

[...] id ipsum fac ut sciamus et nos aliquando aut obiurgare aut communiter consolari desine. Ego si tuam fidem accusarem, non me potissimum tuis tectis crederem; meam amentiam accuso, quod me a te tantum amari quantum ego uellem putaui. Quod si fuisset, fidem eandem, curam maiorem adhibuisses, me certe ad exitium praecipitantem retinuisses, istos labores, quos nunc in naufragiis nostris suscipis, non subisses. 
[...] efforce-toi de m'informer de cela et cesse enfin tes reproches et tes consolations rebattues. Si je m'en prenais à ta bonne foi, ce n'est pas ta maison que je choisirais pour m'y réfugier ; c'est à ma légèreté que je m'en prends, moi qui ai imaginé que tes sentiments à mon égard étaient aussi forts que je le souhaitais. S'il en avait été ainsi, tu n'aurais pas montré davantage de bonne foi à mon égard, mais davantage de sollicitude, tu m'aurais sûrement retenu alors que je courais tête baissée vers ma ruine et ces efforts que tu déploies maintenant, au beau milieu de mon naufrage, tu te les serais épargnés.

41 C'est que les consolations ne lui sont plus d'aucune utilité, à mesure qu'il reprend espoir et entend peser sur les événements. Le reproche et la réflexion sur les conditions du consilium visent avant tout à réorienter la relation épistolaire qui semble s'être limitée jusqu'à présent, de la part d'Atticus, à une fuite, à des plaintes et à des transmissions d'informations.

Cicéron attend d'Atticus un engagement plus grand, un effort de réflexion et, c'est le point le plus frappant, des enquêtes (Cic., Att. 3, 23, 4) :

Tamen in lege nulla esse eius modi caput te non fallit (quod si opus esset, omnes in abrogando <uterentur>), ut Ninnium aut ceteros fugerit, inuestiges uelim, et quis attulerit, et qua re octo tribuni pl. ad senatum de me referre non dubitarint, sibi quod obseruandum illud caput non putabant, eidem in abrogando tam cauti fuerint ut id metuerent soluti cum essent quod ne iis quidem qui lege tenentur est curandum.

Pourtant, tu le sais bien, pareil article n'existe dans aucune loi : or, si c'était quelque chose de nécessaire, tous ceux qui abrogent y auraient recours. Comment Ninnius ou les autres n'y ont-ils rien vu? Tâche de le savoir et aussi qui a introduit cet article et pourquoi les huit tribuns, après avoir proposé mon rappel au Sénat sans la moindre hésitation, parce qu'ils considéraient qu'ils n'étaient pas tenus par cette clause, pourquoi ces mêmes tribuns, quand il s'est agi d'abroger la loi, ont poussé la prudence jusqu'à redouter, alors qu'ils n'étaient pas concernés, des sanctions dont ceux mêmes à qui la loi s'applique n'ont pas à se soucier ${ }^{70}$ ?

L'engagement $d u$ correspondant à tirer au clair une affaire ou à obtenir des informations détaillées est précisément ce qui évitera de se fourvoyer à l'avenir. Pour autant, et, tout en gardant en tête la lacune qui court de février à septembre 57, la correspondance nous donne à voir bien peu de décisions concrètes. À l'inverse, on y rencontre beaucoup de délibérations. Tout comme les réflexions consacrées aux erreurs passées, ces délibérations ont assurément une fonction stratégique : c'est à une véritable mise en scène de la cogitatio et du processus de prise de décision que l'on assiste, et il faut s'interroger sur son sens et sa valeur.

\section{Décider malgré tout ? Mises en scène épistolaires}

Lorsqu'il demande à Lucceius de rédiger l'histoire de son consulat et de son exil, Cicéron juge que l'intérêt de ses tribulations tient aux changements dans les projets des individus et à l'évolution de la situation elle-même ${ }^{71}$. La manière dont l'exilé réagit aux vicissitudes, les décisions qu'il prend ou ne prend pas dans l'adversité sont précisément ce qui tiendra le lecteur en haleine. Il en va de même dans la correspondance, où l'on voit que les interlocuteurs s'inquiètent de l'état de la mens de Cicéron et de sa capacité à décider ${ }^{72}$. Il existe donc une sorte de nécessité narrative présidant à la mise en scène des consilia. Dans ce cadre, ceux-ci figurent moins un véritable support de réflexion qu'un témoignage de Cicéron sur lui-même en vue d'éclairer ses destinataires et, 
surtout, qu'un moyen de construire sa propre image et de développer les stratégies lui permettant d'obtenir ce qu'il souhaite de ses correspondants.

En mars 49, Cicéron se trouve à nouveau dans une situation où il souffre et ne peut agir. Dans son trouble, il se livre à des méditations qu'il nomme consultationes, des délibérations avec soi-même qui lui permettent de traiter de sujets généraux (theseis) liés à la situation politique (Cic., Att. 9, 4, 1-3) :

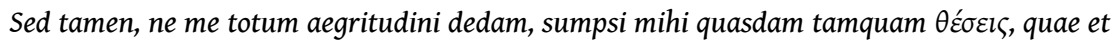

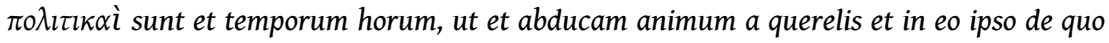

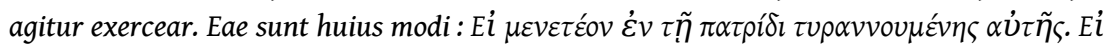

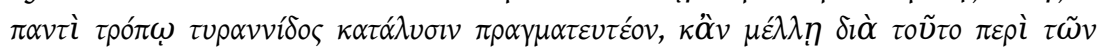

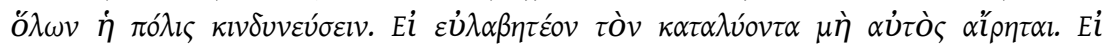

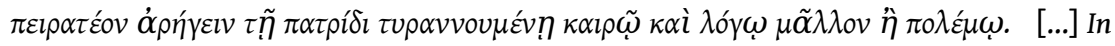
his ego me consultationibus exercens et disserens in utramque partem tum Graece tum Latine et abduco parumper animum a molestiis et $\tau \tilde{\omega} v \pi \rho 0 u ̈ \rho \gamma o v \tau \imath$ delibero.

Pour éviter de m'abandonner tout entier au chagrin, je me propose des sortes de thèses à la fois politiques et liées aux circonstances actuelles, propres à distraire mon esprit de ses plaintes et à l'exercer sur l'objet même qui nous occupe. En voici le genre : si l'on doit rester dans sa patrie tombée sous la puissance d'un tyran? Si l'on doit par tous moyens poursuivre la destruction de la tyrannie au risque d'une ruine totale de la cité ? S'il faut prendre garde que le libérateur ne s'érige pas luimême en tyran? S'il ne faut pas préférer à la guerre, pour aider sa patrie contre la tyrannie, l'opportunité et les voies de la raison? [...] Telles sont les discussions où je m'exerce, débattant le pour et le contre en grec et en latin. Cela distrait un peu mon esprit de ce qui le tourmente, et je précise utilement tel aspect des problèmes ${ }^{73}$.

Cette pratique de la consultatio est à l'origine philosophique, mais elle ouvre la voie à des pratiques rhétoriques qui, par la suite, constitueront le fondement des suasoriae dans le monde de la déclamation ${ }^{74}$. Elle permet, comme le dit Cicéron, de se détacher du présent, de réfléchir aux différentes voies possibles et d'apprécier ses propres obligations, même en l'absence de réelle possibilité d'action. Ce rapport entre l'inaction contrainte et la délibération poussée se retrouve dans notre corpus, sous la même forme (disserere in utramque partem), mais sur des objets d'une autre nature, puisque Cicéron ne débat plus de thèses (soit de sujets abstraits, sans caractéristiques de personnes ou de lieux), mais d'hypothèses, de cas concrets ${ }^{75}$. La lettre semble alors se faire le support d'un débat dont elle fixe les termes. Cicéron expose les possibilités d'action offertes à son correspondant et à lui-même, puis les évalue dans une réflexion in utramque partem (Cic., Att. 3, 15, 6):

Quid enim uides agi posse aut quo modo? per senatumne? at tute scripsisti ad me quoddam caput legis Clodium in curiae poste fixisse, ne referri neue dici liceret. Quo modo igitur Domitius se dixit relaturum? quo modo autem iis quos tu scribis et de re dicentibus et ut referretur postulantibus Clodius tacuit? ac si per populum, poteritne nisi de omnium tribunorum pl. sententia?

D'après toi, que peut-on accomplir, et comment? Passer par le Sénat? Mais tu m'as écrit toi-même que Clodius avait affiché sur la porte de la curie l'un des articles de sa loi interdisant qu'on fasse une proposition ou qu'on prenne la parole <sur ce sujet>. Dans ces conditions, comment Domitius a-t-il pu déclarer qu'il proposerait une motion? Et comment Clodius a-t-il pu rester silencieux alors que ceux que tu mentionnes dans ta lettre s'exprimaient sur ce point et réclamaient une motion? Et si l'on passe par l'assemblée, pourra-t-on y parvenir sans l'appui de tous les tribuns?

Le passage - dont seul le début est cité ici - est formé d'une succession d'hypothèses opposées, présentées dans une arborescence logique où s'opposent affirmations et 
objections, une diuisio. Cette mise en forme rigoureuse de la réflexion est habituelle chez Cicéron, en particulier dans un tel contexte. Elle fait se rencontrer plusieurs influences - que Sophie Aubert retrace dans un article dont je résume ici l'analyse ${ }^{76}$-, depuis la tradition sophistique des dissoi logoi jusqu'à la rencontre des ascendances platoniciennes et aristotéliciennes. Croisant les exigences de ses deux maîtres, celles profondément socratiques - du contra omnia dicere défendues par Philon de Larissa et celles, propres à Antiochus d'Ascalon, de l'in utramque partem dicere, Cicéron s'insère dans des traditions où la réflexion rationnelle repose d'abord sur l'exposé systématique et contradictoire des thèses en présence. Cette manière de détailler les différentes possibilités qui s'offrent à son interlocuteur comme à lui-même procède donc d'un réflexe attendu chez lui ${ }^{77}$, qui lui impose de présenter l'ensemble des arguments qu'il envisage sous une forme solidement structurée. Cicéron expose donc les possibilités et ses choix, en marquant sa préférence pour un rappel par le Sénat. Il fait preuve, comme souvent, d'un mélange de perspicacité et d'imprévoyance. Certes, malgré l'interdiction formulée par la loi de Clodius (et malgré l'opinion d'Atticus), il semble que des discussions ont eu lieu sans coup férir au Sénat, mais pour autant, c'est bien la stratégie législative qui aboutira, puisque, malgré ses affirmations, les discussions au Sénat seront finalement entravées ${ }^{78}$. Cicéron ne perçoit pas encore ces difficultés ou, bien plutôt, le but de cet exposé n'est pas de les détailler. C'est en effet moins dans le sens de la stratégie pure que de l'interaction avec le correspondant qu'il faut le lire. Car si le bel agencement des choix est maintenu pour la forme, le propos glisse rapidement vers le reproche et la plainte (Cic., Att. 3, 15, 6) :

[...] quid de bonis? quid de domo? poteritne restitui? aut si non poterit, egomet quo modo potero? haec nisi uides expediri, quam in spem me uocas? sin autem spei nihil est, quae est mihi uita?

[...] qu'en sera-t-il de mes biens? qu'en sera-t-il de ma propriété ? Pourra-t-on les rétablir? Si on ne le peut pas, comment pourrai-je moi-même être rétabli ? Si tu ne vois pas de solution à tout cela, quel espoir me pousses-tu à nourrir ? Si au contraire il n'y a aucun espoir, quelle est la vie qui m'attend?

Derrière une réflexion présentée d'abord de manière froide, on voit réapparaître une forme d'inquiétude marquée par le raccourcissement des questions et la brièveté de leur succession, mais aussi par la charge émotionnelle des interrogations, par leur objet (non plus les actions à mener, mais la situation de Cicéron) et par leur caractère ouvert : quel espoir, quelle vie s'offrent à l'exilé ? Il s'agit là de questions rhétoriques au sens propre du terme ${ }^{79}$, qui n'appellent pas de réponse, mais qui visent à produire une réaction chez l'interlocuteur. En définitive, la délibération n'est pas le moyen d'atteindre la meilleure décision possible ici, puisqu'Atticus n'a pas besoin qu'on lui présente ces options qu'il connait bien. Elle vise avant tout à agir sur le correspondant, et toute la manœuvre doit se comprendre comme une vaste mise en scène.

Cette lettre Att. 3, 15 de septembre 58 sert trois objectifs. En premier lieu, le respect de la rigueur formelle et l'exposé de la délibération permettent de prouver que Cicéron a gardé toutes ses facultés. Cicéron cherche à contredire ce qu'Atticus lui rapporte à son sujet $^{80}$ : il n'est pas écrasé par la douleur, et s'il souffre, c'est de son aveuglement, contre lequel il a désormais les moyens de lutter. Le $\S 6$ de la lettre, avec la diuisio qu'il contient, cherche d'abord à adopter la forme d'un développement rationnel, pour montrer que Cicéron n'a pas perdu sa force intellectuelle et sa clairvoyance (Cic., Att. 3, $15,2)$ : 
Ad primam tibi hoc scribo, me ita dolere ut non modo a mente non deserar sed id ipsum doleam, me tam firma mente ubi utar et quibuscum non habere.

À la première je réponds ceci : oui, je souffre, mais sans que pour cela mes facultés intellectuelles m'abandonnent ; bien plus, ce qui précisément me fait souffrir, c'est que, faute d'occasion et de société, leur vigueur reste sans emploi ${ }^{81}$.

Il faut replacer cette affirmation dans le contexte de l'interaction avec Atticus : jointe aux reproches, elle sert la stratégie de réorientation de la communication entre les deux correspondants. Ainsi, la forme rationnelle du message appuie la demande de Cicéron lorsqu'il exige d'Atticus qu'il abandonne l'émotion pour en venir à la réflexion.

51 Mais il s'agit par ailleurs de respecter les conventions épistolaires : cette délibération succède à des conseils formulés de façon directe, mais Cicéron a bien conscience que ce type d'échange n'est pas possible. Après avoir indiqué la marche suivre à Atticus, il s'interrompt soudain (Cic., Att. 3, 15, 6):

Verum est stultum me praecipere quid agatis aut quo modo. Vtinam modo agatur aliquid! In quo ipso multa occultant tuae litterae, credo ne uehementius desperatione perturber. Quid enim uides agi posse aut quo modo?

Mais je m'égare en vous prescrivant ce qu'il faut accomplir et comment vous y prendre: puisse-t-on au moins faire quelque chose! Tes lettres me cachent beaucoup de choses sur ce point - j'imagine que tu le fais parce que tu crains qu'en perdant espoir, je ne me trouble trop fortement. D’après toi, que peut-on accomplir, et comment?

52 Cicéron abandonne la prescription et passe à un système de questions pour indiquer la marche à suivre, mais la formulation reste la même dans les deux cas (quid agatis aut quo modo), ce qui n'échappe sans doute pas au correspondant tant la manœuvre est appuyée. Il s'agit là de trouver une manière acceptable de conseiller ses propres soutiens et, surtout, d'exercer sur eux une pression plus forte encore.

Ce troisième usage - la pression - tient à la portée émotionnelle donnée à la délibération. Souvent, Cicéron met en scène la contrainte qui s'exerce sur sa volonté afin d'échapper à des reproches. Le 29 avril 58, en Fam. 14, 4, 3, Cicéron débat de la venue de Terentia; son refus représente l'un des rares cas où la délibération est aussi précisément exposée (Cic., Fam. 14, 4, 3) :

0 me perditum, o me adflictum! quid nunc? rogem te ut uenias, mulierem aegram, et corpore et animo confectam? non rogem? sine te igitur sim? opinor, sic agam : si est spes nostri reditus, eam confirmes et rem adiuues; sin, ut ego metuo, transactum est, quoquo modo potes, ad me fac uenias.

Ah! quel désastre ! quelle douleur ! Puis-je à présent te demander de me rejoindre, pauvre femme malade, à bout de forces et de courage? Ne pas te le demander? Rester privé de ta présence? Voici, je crois, ce que je ferai: si je puis espérer rentrer, je te prierai d'aider à la réalisation de cet espoir ; si en revanche, comme je le crains, c'en est fait, arrange-toi, par tous les moyens possibles, pour venir me retrouver ${ }^{82}$.

54 La décision est entièrement prise dans un contexte émotionnel et elle est décrite comme une souffrance. Cette présentation permet de justifier une décision qui n'est ni facilement acceptable pour Terentia ni vraiment présentable pour Cicéron. L'enjeu est donc d'imposer un choix ou une modalité d'action. De fait, dans notre corpus, on remarque que les disjonctions si... sin... qui fondent le processus de diuisio sont majoritairement factices ${ }^{83}$.

Les premiers emplois de cette structure concernent des délibérations d'ordre géographique et recensent de vraies alternatives. Mais par la suite, la diuisio consiste 
uniquement à opposer une possibilité d'action à un abandon ou au désespoir (Cic., Att. 3, 23, 5):

Qua re oro te ut, si qua spes erit posse studiis bonorum, auctoritate, multitudine comparata rem confici, des operam ut uno impetu perfringatur, in eam rem incumbas ceterosque excites. Sin, ut ego perspicio cum tua coniectura tum etiam mea, spei nihil est, oro obtestorque te ut Quintum fratrem ames [...].

Aussi, je t'en conjure, s'il y a quelque espoir que l'on puisse aboutir en s'assurant le zèle des gens de bien, l'autorité de personnalités influentes, l'intervention des masses populaires, fais en sorte qu'un seul assaut ait raison de tous les obstacles, donne-toi à cette tâche et excite l'ardeur des autres; si en revanche, comme mes propres calculs aussi bien que les tiens me le laissent voir, il n'y a rien à espérer, je te prie et te supplie d'entourer d'affection mon frère Quintus [...] ${ }^{84}$.

Dans ce cas, Cicéron n'expose pas une délibération véritable, mais exerce une pression. L'exposé pathétique auquel il se livre tente de pousser le correspondant à l'action ${ }^{85}:$ il s'agit d'agir ou de succomber. Le choix laissé au correspondant est pour le moins orienté.

Ces trois stratégies se croisent, bien sûr. Quand il s'agit d'imposer à Terentia qu'elle demeure à Rome, Cicéron utilise la forme de la disputatio pour donner à son argument un tour pathétique. Si l'espoir demeure, qu'elle reste, si tout espoir est perdu, qu'elle vienne le retrouver et partager sa ruine ${ }^{86}$. On ne saurait mieux la contraindre tout en respectant les bienséances; la délibération apparaît pour ce qu'elle est avant tout ici, un jeu de conventions, une manière d'établir avec le correspondant une communication à la fois efficace et acceptable. Il reste que notre corpus montre une évolution très nette sur ce point. Le 29 novembre 58 , Cicéron en arrive à exprimer sa volonté de manière beaucoup plus ferme sur ce même sujet (Cic., Fam. 14, 3, 5) :

Quod scribis te, si uelim, ad me uenturam, ego uero, cum sciam magnam partem istius oneris abs te sustineri, te istic esse uolo. Si perficitis quod agitis, me ad uos uenire oportet; sin autem - sed nihil opus est reliqua scribere.

Tu m'écris que tu es prête à me rejoindre, si je le désire; mais sachant que la plus grande partie de la tâche à accomplir repose sur tes épaules, je veux que tu sois làbas. Si vous aboutissez, c'est moi qui dois vous rejoindre ; et dans le cas contraire pas besoin d'en écrire davantage ${ }^{87}$.

Cicéron justifie sa décision en mentionnant une alternative : si tout suit son cours, il les retrouvera (et Terentia n'aura pas à le rejoindre), dans le cas contraire, il ne développe pas les possibilités. Terentia, en effet, sait bien ce qu'il en est. L'émotion a disparu, la diuisio se développe sur un terrain commun beaucoup plus rationnel et débouche sur un ordre (uolo).

Il faut pourtant remarquer que cette courte deliberatio est la dernière du corpus d'exil ${ }^{88}$. Les mois qui séparent Cicéron de son retour ont peut-être permis le développement d'une délibération plus franche et plus concrète, dans la direction indiquée par Fam. 14, 3, 5, mais les enjeux de l'édition antique - et, sans doute, la volonté de créer un récit cohérent et dominé par l'émotion ${ }^{89}$ - ne nous laissent pas percevoir aujourd'hui cet aspect possible de l'échange. Telles qu'elles nous ont été transmises, les lettres d'exil restent centrées sur l'expression du désespoir et sur le reproche, dessinant ainsi une image très orientée des réactions de Cicéron face à l'exil. 


\section{Conclusion}

actions, sensées ou non, seront jugées par tous à leur résultat (Cic., Fam. 1, 7, 5) :

Sed haec sententia sic et illi et nobis probabatur ut ex euentu homines de tuo consilio existimaturos uideremus; si cecidisset ut uolumus et optamus, omnis te et sapienter et fortiter, si aliquid esset offensum, eosdem illos et cupide et temere fecisse dicturos.

Mais si telle est la pensée de Pompée et la mienne, c'est sous la réserve suivante : nous ne nous dissimulons pas que l'opinion jugera ton entreprise à ses résultats ; s'ils sont conformes à ce que nous avons en tête et à ce que nous souhaitons, tout le monde dira que tu as agi en homme sage et énergique; si tu te heurtes au moindre obstacle, les mêmes te taxeront d'ambition folle et téméraire ${ }^{90}$.

61 La bonne prise de décision est en définitive celle qui aboutit au succès - manière, sans doute, d'appeler le proconsul à la prudence et de lui rappeler le risque qu'il y aurait à intervenir en dehors de sa province sans être sûr de son fait. Mais derrière l'apparente tautologie, c'est bien une stratégie de désengagement qui apparaît, comme le montre le syntagme tuum consilium qui annule à lui seul tout le processus de conseil, pour imputer à Lentulus l'entière responsabilité de la décision ${ }^{91}$. Cicéron développe d'ailleurs cet argument en mettant de côté les conseils qu'il a pu donner et en imputant à Lentulus non plus seulement la décision, mais la faculté de la prendre correctement (Cic., Fam. 1, $7,5)$ :

Quare quid adsequi possis non tam

facile est nobis quam tibi, cuius prope in conspectu Aegyptus est, iudicare.

Voilà pourquoi il nous est moins facile qu'à toi, qui as l'Égypte sous les yeux ou

presque, d'évaluer ce que tu peux accomplir.

Le conseil, ainsi, tourne court - à Lentulus de juger ce qu'il convient de faire -, ou plus exactement, il se détourne. On ne peut croire en effet que Lentulus ait demandé à Cicéron son avis sur la situation d'Égypte: ses demandes ne portaient que sur la possibilité et l'opportunité politique de l'invasion, et c'est précisément cette question que Cicéron laisse de côté en s'intéressant aux seules difficultés du terrain ${ }^{92}$. Si le succès suffit à produire l'opportunité politique, alors tout est entre les mains de Lentulus. On ne saurait mieux fuir l'officium du conseil et les impératifs de l'amicitia.

Cette fuite attire l'attention sur l'attitude générale de Cicéron à l'égard de Lentulus. Si son amitié et son respect pour lui sont réels et profonds ${ }^{93}$, sa prudence dans le conseil est manifeste. Contraint de donner son avis, il se garde de tout consilium trop précis qui lui ferait encourir des reproches par la suite. Pire encore, il reste vague dans les informations qu'il fournit, au point que Lentulus réclame des précisions - qui ne viendront pas ${ }^{94}$. À l'inverse, il entretient l'espoir de son correspondant, proclame le sien ${ }^{95}$ - les ennemis de Lentulus seront un jour défaits - et l'appelle à une fermeté toute philosophique ${ }^{96}$. Les maux de Lentulus, quoique moins terribles, sont à l'image des siens nous dit-il ${ }^{97}$. Mais si Lentulus est un nouveau Cicéron, est-ce à dire que Cicéron se comporterait désormais comme Atticus en fuyant à son tour ses devoirs d'amicus? À lire ses réflexions au sujet de l'Égypte, on serait tenté de le croire.

Dès lors, c'est la relation même à Atticus qui doit être réinterprétée et lue comme la version extrême d'un mode de communication normal. À un personnage affaibli et lointain réclamant conseils et soutien, répond un ami certes prévenant, un peu contraint, mais surtout prudent, et dont les conseils sont moins de véritables aides à la décision que des marques d'intérêt et des moyens d'interaction. Les stratégies 
épistolaires de Cicéron, lorsqu'il réclame conseils et délibérations, ne sont donc pas des manipulations, mais des postures répondant non à une trahison de ses correspondants, mais à leurs propres stratégies de fuite, en définitive normales et courantes. Dans ce jeu d'échanges, chacun tente de remplir son officium de la façon la plus efficace et la plus sûre possible: sans doute vaut-il mieux être accusé d'avoir trop peu conseillé que de l'avoir mal fait, comme les critiques de Cicéron envers Hortensius le donnent à penser. Face au risque de l'erreur, face au poids de la délibération, le demandeur est condamné à rester seul maître de sa décision. Encore faut-il, bien sûr, qu'il soit réellement en état de la prendre.

\section{BIBLIOGRAPHIE}

\section{Textes anciens}

Cicéron, Correspondance, II, texte établi et trad. par L.-A. Constans, CUF, Paris, 1935.

Cicéron, Correspondance, V, texte établi et trad. par J. Bayet, CUF, Paris, 1964.

Cicéron, Correspondance, VI, texte établi, trad. et annoté par J. Beaujeu, CUF, Paris, 1993.

Cicero's Letters to Atticus, II, 58-54 B.C., 46-93 (Books III and IV), ed. by D. R. Shackleton Bailey, Cambridge Classical Texts and Commentaries 4, Cambridge, 1965.

Hermagoras, Fragments et témoignages, textes édités, trad. et commentés par Fr. Woerther, CUF 486, Paris, 2012.

\section{Textes modernes}

AUBERT S. 2014, «L'influence de la disputatio in utramque partem sur la correspondance de Cicéron », VL 189-190, p. 21-39.

BEARD M. 2002, « Ciceronian Correspondences: Making a Book out of Letters », in T. P. Wiseman (éd.), Classics in Progress. Essays on Ancient Greece and Rome, British Academy Centenary Monographs, Oxford, p. 104-144.

BERNARD J. 2013, La sociabilité épistolaire chez Cicéron, Babeliana 16, Paris.

BONNER S. F. 1949, Roman Declamation in the Late Republic and Early Empire, Liverpool.

CARCOPINO J. 1947, Les secrets de la correspondance de Cicéron, I, Paris.

CLAASSEN J.-M. 1992, « Cicero’s Banishment: Tempora et Mores », AClass 35, p. 19-47.

CLARKE M. L. 1951, « The Thesis in Roman Rhetorical Schools of the Republic », CQ 1, p. 159-166.

FAIRWEATHER J. 1981, Seneca the Elder, Cambridge Classical Studies, Cambridge.

GARCEA A. 2005, Cicerone in esilio. L'epistolario e le passioni, Spudasmata 103, Hildesheim - New York. 
HABINEK T. N. 1990, « Towards a History of Friendly Advice: The Politics of Candor in Cicero's de Amicitia », Apeiron 23, p. 165-186.

HELLEGOUARC'H J. 1972, Le vocabulaire latin des relations et des partis politiques sous la République, $2^{\mathrm{e}}$ tirage revu et corr., Coll. d'études anciennes, Paris [ $1^{\mathrm{er}}$ tirage : Publications de la Faculté des lettres et sciences humaines de l'Université de Lille 11, 1963].

HOFF F. 1983, «Interrogation, interrogation rhétorique et exclamation en latin », in

H. Pinkster (éd.), Latin Linguistics and Linguistic Theory. Proceedings of the 1st International Colloquium on Latin Linguistics, Amsterdam, April 1981, Studies in Language Companion Series 12, Amsterdam, Benjamins, p. 123-129.

HUTCHINSON G. O. 1998, Cicero's Correspondence. A Literary Study, Oxford.

KELLY G. P. 2006, A History of Exile in the Roman Republic, Cambridge, Cambridge.

LÉVY C. 2006, «Textes antiques, enjeux contemporains : J. Carcopino lecteur de la correspondance de Cicéron ", in P. Laurence, F. Guillaumon (éds), Epistulae antiquae. IV, Actes du IV colloque international «L'épistolaire antique et ses prolongements européens », Université François-Rabelais, Tours,

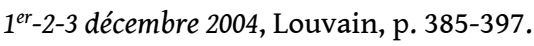

LINTOTT A. 2008, Cicero as Evidence. A Historian's Companion, Oxford.

MOREAU P. 1987, « La lex Clodia sur le bannissement de Cicéron », Athenaeum 65, p. 465-492.

- 1989, « La rogatio des huit tribuns de 58 av. J.-C. et les clauses de sanctio réglementant

l'abrogation des lois ", Athenaeum 164, p. 151-178.

ROSENMEYER T. G. 1990, « Decision-Making », Apeiron 23, p. 187-218.

SCHMIDT-RADEFELDT J. 1977, « On So-Called 'Rhetorical' Questions », Journal of Pragmatics 1, p. 375-392.

SIANI-DAVIES M. 1997, « Ptolemy XII Auletes and the Romans », Historia 46, p. 306-340.

WHITE P. 2010, Cicero in Letters. Epistolary Relations in the Late Republic, Oxford - New York.

\section{NOTES DE FIN}

1. Cf. Cic., Q. fr. 1, 1, 37 ; Fam. 2, 4, 1; 4, 13, 1 ; Att. 7, 5, 4-5, et Bernard 2013, p. 81-88.

2. En l'absence de mention contraire, les traductions sont les nôtres.

3. Voir sur ce point l'analyse de Beard 2002, p. 125-127, qui lit Att. 3, 1 comme le récit dramatique d'une rencontre manquée, ou sans cesse différée, entre les deux correspondants.

4. La délibération en face à face est encore mentionnée en Att. 3, 2; 3, 3 ; 3, 6.

5. Cf. Cic., Fam. 15, 14, 3.

6. Cic., Fam. 1, 5a, 3.

7. Cf. Cic., Fam. 14, 1, 2 : [...] mihi deest consilium.

8. Voir. Lévy 2006.

9. Voir les développements consacrés au «velléitaire impénitent » (Carcopino 1947, p. 394-399) et, plus encore, l'analyse de la correspondance d'exil (ibid., p. 318-325) qui traduit d'après l'auteur « le désarroi de son esprit, la faiblesse de son caractère et son manque absolu de dignité » (ibid., p. 320).

10. Cic., Att. 3, 14, 1 : Scio nos nostris multis peccatis in hanc aerumnam incidisse.

11. Beard 2002, en particulier p. $125 \mathrm{sq}$.

12. Cf. également Cic., Q. fr. 1, $3,3$. 
13. Cicéron avait d'excellentes relations avec Sicca (cf. par ex. Att. 16, 6, 1, qui précise, à propos de la maison de Sicca, ibi tamquam domi meae scilicet) et pensait donc pouvoir rester en sa compagnie sans difficulté et sans risque.

14. Shackleton-Bailey (éd.) 1965, p. 140-141. Sur les lois clodiennes, voir Moreau 1987 ; Kelly 2006, p. 225-237.

15. Trad. L.-A. Constans 1935 modifiée.

16. Dion Cassius, $38,17,7$.

17. Cic., Planc. 96. D. R. Shackleton-Bailey (1965, p. 141) note que la province de Vergilius (Malte et la Sicile) était en tout état de cause située en deçà de la limite fixée par la loi.

18. Trad. L.-A. Constans 1935.

19. Kelly 2006, p. 54-65.

20. Trad. L.-A. Constans 1935.

21. Kelly 2006, p. 77-81.

22. Trad. L.-A. 1935 modifiée.

23. Le même abandon se rencontre en Att. 3, 23, 5, où Cicéron charge Atticus de veiller à ce que Quintus préserve ses propres intérêts, mais ne lui donne aucune indication précise.

24. Moreau 1989 ; Kelly 2006, p. 121-122.

25. Trad. L.-A. Constans 1935 modifiée.

26. Cf. Cic., Att. 3, 27.

27. Voir ci-dessus, note .

28. Sur cette stratégie et son originalité, voir Kelly 2006, p. 123-125.

29. Rosenmeyer 1990, p. 196-197.

30. Cic., Att. 3, 9, 3.

31. Cic., Q. fr. 1, 1, 37 ; Fam. 2, 4, 1 ; Att. 7, 5, 4-5. Sur les lettres de ce type, voir Bernard 2013, p. 85-86.

32. Cic., Att. 3, 13, 2 : Nunc quoniam iam est Cyzicum nobis eundum, quo rarius ad me litterae perferentur [...].

33. Cic., Att. 3, 14, $1 ; 15,7 ; 20,3 ; 22,4 ; 23,5 ; 4,8,2 ; 8 \mathrm{a}, 1$; Fam. 14, 1, 5 ; 2, 4 .

34. Cic., Att. 3, 15, 8 (omnia) ; 18, 2 (me fac de tota causa nostra certiorem; omnia) ; 24, 2 (tota res); Fam. 14, 3, 5 (uelim omnia diligentissime perscribas).

35. C'est cette organisation qui permet une prise de décision rationnelle: Cic., Att. 3, 23, 5 : Tertia est epistula prid. Id. Nou. data, in qua exponis prudenter et diligenter quae sint quae rem distinere uideantur, de Crasso, de Pompeio, de ceteris.

36. Cic., Att. 3, 10, 3.

37. Cic., Att. 3, 4, 1.

38. Trad. J.-A. Constans 1935 modifiée.

39. Garcea 2005, p. 205-206.

40. Voir sur ce point Garcea 2005, p. 205, et son analyse des réflexions de Cicéron sur l'insanitas comme perte de contrôle de la part rationnelle de l'âme en Tusc. 3, 10.

41. Cic., Att. 3, 13, $2 ; 15,1 ; 15,2$.

42. Cf. en particulier Dion Cassius, 38, 19-40, et l'exhortation fictive de Philiscus à Cicéron.

43. Sur ces trois notions, cf. Garcea 2005, p. 205-206.

44. Cic., Att. 3, 9, 2 : [...] me tuae litterae sustentant [...].

45. Cic., Att. 3, 18, 1 sq. ; 3, 23, 1 sq.

46. Cic., Att. 3, 12 : Tu quidam sedulo argumentaris quid sit sperandum. Voir aussi Att. 3, 23, 1 ; 23, 5.

47. Trad. J.-A. Constans 1935 modifiée.

48. Cic., Tusc. 4, 80, analysé par Garcea 2005, p. 198.

49. Cic., Att. 3, 8, 4 : ex culpae nostrae recordatione.

50. Cic., Att. 3, 9, 1 : mei peccati luo poenas ; 3, 15, 4 : in me enim ipsum peccaui uehementius ; Q. fr. 1, 4, 1 : nullum est meum peccatum nisi quod iis credidi [...]. 
51. Cf. en particulier Cic., Att. 3, 7, 2.

52. Cic., Att. 3, 8, 4 : Cuius enim scelere impulsi et proditi simus iam profecto uides; atque utinam ante uidisses neque totum animum tuum maerori mecum simul dedisses! Qua re cum me adflictum et confectum luctu audies, existimato me stultitiae meae poenam ferre grauius quam euenti, quod ei crediderim quem esse nefarium non putarim.

53. Trad. J.-A. Constans 1935 modifiée.

54. Trad. J.-A. Constans 1935 modifiée.

55. Cic. Fam. 1, 1-7. Sur l'affaire d'Égypte, voir en particulier Siani-Davies 1997; Lintott 2008, p. 191-194.

56. Cf. Cic., Att. 4, 1, 1 (la première lettre post reditum conservée).

57. Cic., Att. 3, 19, 3 ; 4, 3, 5

58. Cic., Q. fr. 1, 4, 1 ; Att. 4, 3, 5 .

59. Cic., Att. 3, 8, 4 : Cuius enim scelere impulsi et proditi simus iam profecto uides; atque utinam ante uidisses neque totum animum tuum maerori me cum simul dedisses!

60. Sur la notion d'officium dans les relations sociales, voir Hellegouarc'h 1972, p. 152-163. Sur le lien entre correspondance et officia, voirBernard 2013, p. 76-81.

61. Cic., Off. 1, 58.

62. Sur la nouveauté de cette posture, voir Habinek 1990 et les remarques de White 2010, p. 131-132.

63. Cic., Amic. 44 et 88.

64. Cic., Fam. 1, 2, 4; 1, 2, 3; 1, 5a, 3; 1, 7, 3.

65. Cic., Fam. 1, 5, 4 : a me nullum tempus praetermittitur de tuis rebus et agendi et cogitandi.

66. White 2010, p. 129.

67. Trad. Beaujeu 1993.

68. Cic., Att. 3, 15, 2. Sur cette topique, voir Hutchinson 1998, p. 36-37.

69. Voir l'analyse de Claassen 1992, p. 29-31.

70. Trad. J.-A. Constans modifiée (le texte est celui de Shackleton-Bailey [éd.] 1965). Cf. deux autres demandes du même type en Cic., Att. 4, 8a, 4 ; Q. fr. 1, 4, 5.

71. Cic., Fam. 5, 12, $6:$ [...] habet enim uarios actus multasque <mut $>$ ationes et consiliorum et temporum.

72. Cic., Att. 3, 15, 1-2.

73. Trad. Bayet 1964 modifiée.

74. Sur l'origine des suasoriae et ses relations aux "thèses " des traditions philosophiques et rhétoriques antérieures, voir Clarke 1951 ; Bonner 1949, p. 1-50 ; Fairweather 1981, p. 104-131.

75. Sur la différence entre « thèse » et " hypothèse ", cf. surtout Cic., Inv. 1, 8, et Hermagoras T14, 16, 17, 19, 20 Woerther et le commentaire de Woerther (éd.) 2012, p. 79-101.

76. Aubert 2014.

77. Cic., Att. 2, 3, 3.

78. Kelly 2006, p. 122-124.

79. Schmidt-Radefeldt 1977 ; Hoff 1983.

80. Cic., Att. 3, 15, 2.

81. Trad. J.-A. Constans 1935 modifiée.

82. Trad. J.-A. Constans 1935.

83. Il faut distinguer cependant les alternatives portant sur les actions que Cicéron lui-même et ses soutiens peuvent entreprendre d'une part, et les comportements possibles des autres acteurs politiques d'autre part (si... sin... servant alors à lister des éventualités et leurs conséquences, mais pas des actions à entreprendre, cf. Att. 3, 15,5). Les occurrences de la première catégorie, seules pertinentes pour notre propos, sont les suivantes : Att. 3, 5, 1; 3, 9, 2; 3, 10, 1; 3, 12, 2 ; 3, 15, 6-7 ; 3, 23, 1 ; 3, 23, 5 ; 4, 1, 7 ; Fam. 5, 12, 10 ; 14, 2, 3 ; 14, 3, 5 ; 14, 4, 3 ; 14, 4, 4; Q. fr. 1, 3, 5 ; 1, 4 4-5.

84. Trad. J.-A. Constans 1935. 
85. La manœuvre est éclairée par un cas où la démarche est plus explicite (Cic., Q. fr. 1, 4, 5), où l'alternative est présentée de manière factice.

86. Cic., Fam. 14, 4 , 3.

87. Trad. J.-A. Constans 1935 modifiée.

88. La disputatio qui apparaît en Att. 3, 24, 1, en décembre 58, est un discours rapporté et ne doit pas être attribuée à Cicéron.

89. Voir l'analyse de Beard 2002, p. 125-127.

90. Trad. J.-A. Constans 1935 modifiée.

91. Voir l'analyse de White 2010, p. 133.

92. Le « conseil » est répété en Cic., Fam. 1, 7, 6 : in hac ratione quid res, quid causa, quid tempus ferat, tu facillime optimeque perspicies.

93. Bernard 2013, p. 456-457.

94. Cic., Fam. 1, 7, 2. Voir sur ce point l'analyse de White 2010, p. 85.

95. Cic., Fam. 1, 6, 1.

96. Cic., Fam. 1, 6, 2.

97. Cic., Fam. 1, 6, 2.

\section{RÉSUMÉS}

Dès son départ en exil, Cicéron doit prendre des décisions : où s'installer, comment assurer la sécurité des siens, quelle stratégie adopter pour garantir son retour à Rome. Mais la situation dans laquelle il se trouve - distance, affaiblissement politique, solitude, inquiétude - le prive en grande partie de sa faculté de délibération et des moyens habituels du consilium capere. Dans la correspondance des années 58-57, la prise de décision est plus difficile encore qu'à l'habitude, et donne lieu à des délibérations qui portent autant sur l'avenir que sur les erreurs que Cicéron pense avoir commises: c'est à une véritable mise en scène du consilium capere que se livre l'épistolier, et à une réflexion sur ce qui permet ou non de trancher une alternative. Cet article montre que, tout au long de l'exil, ces exposés représentent moins de véritables supports de réflexion que des outils stratégiques permettant de construire l'image de l'épistolier et d'influencer ses correspondants.

As soon as he left Rome and went into exile, Cicéron had to make choices : where to settle, how to make sure his family would not be harmed, how to obtain his recall. Being an exile, he was generally unable to make actual choices, and the letters written in 58-57 BCE show how difficult it proved for him to decide (consilium capere) anything. In his correspondence, he contemplates future issues, but also gives a lot of thoughts to his past errors. This article shows that when he's assessing the situation and discussing the available options, Cicero he's not actually involved in a decision-making process, but uses his deliberations as a tool for shaping his own persona and influencing his correspondents.

\section{INDEX}

nomsmotscles Antiochus d'Ascalon, Aristote, Cicéron, Dion Cassius, Hermagoras de Temnos, Lucceius (Lucius), Philon de Larissa

Keywords : correspondence, rhetoric, consilium, deliberation, decision-making, exile

Mots-clés : correspondance, rhétorique, consilium, délibération, prise de décision, exil 
AUTEUR

CHARLES GUÉRIN

Université Paris Est - Créteil, Institut universitaire de France 